\title{
LINGUAGEM ONTOLÓGICA E TRADICIONALISMO EM COMUNIDADES ELETRÔNICAS CATÓLICAS
}

\author{
Emerson Sena da Silveira ${ }^{1}$
}

Resumo: Neste texto, investiga-se a emergência de comunidades católicas dentro das redes sociais eletrônicas. Essas comunidades, compostas de duas dimensões (pequenos grupos estáveis com fortes laços sociais e grupos maiores, mais instáveis com laços frouxos, baseados em afinidade virtual), arregimentam muitos adeptos jovens. A partir de breve trabalho de campo digital, foram pesquisados durante três meses diversos grupos católicos tradicionalistas. Argumenta-se que o catolicismo tradicionalista dessas comunidades eletrônicas desenvolve formas de pertença baseadas em algumas estratégias de gestão identitárias: criação de perfis comunitários e pessoais com elementos simbólicos da tradição católica; adoção de personagens (virgem Maria, santos, santas, papas e outros); uso de uma linguagem teológica conservadora, que oscila entre o uso de marcadores discursivos clássicos (linguagem escolástica) e marcadores discursivos híbridos (linguagem sincopada, pós-moderna, com uso de imagens montadas e slogans curtos, com efeito retórico). A ontologia da tradição passa a ser construída no fluxo midiático eletrônico e no embate dessas comunidades eletrônicas católicas com outros grupos religiosos católicos e não católicos nesse mundo cibernético. Ao fim da pesquisa, constatou-se, que, embora pequenos, esses grupamentos virtuais crescem e estão em processo de consolidação no espaço cibernético.

Palavras-chave: Comunidades Eletrônicas Católicas. Tradição. Rede. Linguagem Ontológica.

Abstract: In this paper, we investigate the emergence of the catholic communities in the electronic social networks. These communities are composed of two dimensions (small stable groups with strong social ties and larger groups, more unstable with loose ties, based on virtual affinity), these have many young devout fans. From a digital research, many traditionalist Catholic groups were surveyed during three months. It is argued that the traditionalist Catholic communities develop these electronic forms of belonging based on some identity management

1 Doutor em Ciência da Religião, Programa de Pós-Graduação em Ciência da Religião, Universidade Federal de Juiz de Fora, Brasil. E-mail: emerson.pesquisa@gmail.com.

Debates do NER, Porto Alegre, Ano I5, N. 25, P. 215-239, JAn./Jun. 2014 
strategies, creation of community and personal profiles with symbolic elements of the Catholic tradition; adoption of characters (the Virgin Mary, saints, popes and others); and the use of classical discourse markers (scholastic language) that varies between the of a conservative theological language and the hybrid discourse markers (postmodern syncopated language, using pictures and short slogans with rhetorical effect). The ontology of tradition has been built in electronic media flow and the clash of those Catholic electronic communities with other religious groups, Catholics and non-Catholics in this cyber world. At the end of study, it was found that although small, these virtual clusters grow and are in the process of consolidation in cyberspace.

Keywords: Catholic Electronic Communities. Tradition. Network. Ontology Language.

\section{INTRODUÇÃO}

Neste artigo, busca-se analisar a transformação das antigas e tradicionais formas de construção identitária e a criação de lógicas pós-tradicionais de identidade. (Giddens, 1991; 2005; Mafesolli, 2001).

Assim como surgem novas formas de comunidade, baseadas na afeição, no compartilhamento de sentimentos e afinidades, emergem novas formas de associação, de adesão, de crença e pertença, concorrendo, potencializando e problematizando as antigas formas de recrutamento.

A multiplicação das formas de linguagem e de afinidade desses novos círculos sociais representa, portanto, uma consequência dessa ampliação e desregulação (e também novas formas de regulação) impactando as comunidades religiosas tradicionais e normativas. É válido lembrar que, no espaço-tempo da modernidade, muitas comunidades religiosas ainda viviam encrustadas em territórios sociais moldados por fronteiras geográficas e culturais inscritas em um espaço territorial/urbanístico/arquitetônico planejado, controlado e ordenado.

Com o advento da cibernética, aprofundaram-se as mudanças nas formas de vinculação e criação de identidades, e as mídias eletrônicas, por sua vez, desprovidas de dimensões espaciais duras, recolheram-se sob o signo de uma temporalidade peculiar: difusão instantânea, fusão de fronteiras

Debates do NER, Porto Alegre, ANo I5, N. 25, P. 215-239, JAN./Jun. 2014 
entre aqui e lá, entre outros fenômenos que possibilitaram a emergência de comunidades eletrônicas.

Nesse ínterim, mesmo deslocadas, as desigualdades e as antigas formas de associação e pertença são redistribuídas, convivendo com as novas formas. Por vezes, essas duas formas articulam-se e sobrepõem-se umas às outras, de forma que uma comunidade religiosa tradicional pode se projetar no espaço cibernético, difratando-se em uma comunidade eletrônica.

Essa convivência entre antigas e novas formas de adesão, pertença e crença, marca o catolicismo que, no decorrer de sua longa jornada histórica, inicia uma complexa interação com os novos meios de comunicação e associação.

Nesse sentido, pode-se perceber que, em especial a partir da segunda década dos anos 2000, o desenvolvimento das novas redes eletrônicas, o barateamento de tecnologias e aparelhos de conexão com o espaço cibernético, bem como sua disseminação a amplas camadas da população, permitiram a emergência de uma rede de associação e interação entre pessoas com ideias ou interesses afins, talvez uma comunidade eletrônica.

No caso do catolicismo, essa rede adensou-se com o tempo, multiplicando-se o número de blogs pessoais, sites, páginas eletrônicas, perfis no Facebook, contas no Twitter e no Youtube que expressam motivos, interesses, ideias e desejos religiosos. Uma parte dessa rede é tradicionalista, por defender explicitamente valores inegociáveis enfileirados em torno de dois princípios na visão tradicionalista-conservadora: uma verdade única como existência iniludível (Deus, Igreja, Revelação e Sagradas Escrituras) e a família heterossexual cristã como ordem natural (homem, mulher e filhos com papéis e funções reprodutivas).

Na nova carga semântica do discurso católico, aqui chamada de tradicionalidade conservadora, o vínculo entre esses dois princípios é visível. Um sustenta o outro e um permite ao outro exercer domínio discursivo dos fatos, fenômenos, grupos e ações sociais e, com isso, é construída uma teia fechada de interpretação, veiculada pela recusa de algumas palavras utilizadas por movimentos feministas e outros, além da defesa de outras. É na rede de blogs, páginas e sites que é possível identificar a conexão entre esses princípios.

Debates do NER, Porto Alegre, ANo I5, N. 25, P. 215-239, Jan./Jun. 2014 
É preciso lembrar que entre o início da República e a época atual, houve a formação de muitos grupos defendendo a restauração católica, entre os quais a TFP (Sociedade Brasileira de Defesa da Tradição, Família e Propriedade). Todavia, as movimentações reativas, estratégias de pressão sobre os poderes constituídos e a abertura à influência do pentecostalismo (carismatismo católico ${ }^{2}$, padres cantores etc.), não detiveram a curva descendente do catolicismo professado como religião, ainda que este seja portador de vastos sincretismos (com religiōes de matriz africana) e variedades internas (comunidades eclesiais de base, pastorais sociais, renovação carismática católica etc.).

Assim, em 1872, 99,7\% da população declarava-se católica; em 1970, 91,8\%; em 1980, 88\%; em 1991, 80\%; em, 1994, 74,9\%; em 2000, 73,6\%;

2 Surgida em 1966-1967, em universidades norte-americanas, esse movimento (renovação carismática católica) expande-se pelo mundo, chegando ao Brasil, em 1969, e passando, a partir daí, por uma considerável expansão e diversificação, paralelamente à sua subordinação institucional e a "linhas de fuga" (ou de insubordinação institucional). Esse movimento esteve originalmente em contato próximo com grupos pentecostais, sendo atrelado às estruturas católicas pelo papa Paulo VI, que designou um cardeal belga, Suenens, para romanizar o movimento. No Brasil, percorreu uma trajetória de complexificação, com diversas práticas e agrupamentos: comunidades de vida e aliança, associações de leigos reconhecidas pelo direito canônico e pelo civil, ministérios ou grupos organizativo-mobilizadores temáticos (Comunicação social, Cura e libertação, Música e artes, Jovem, Formação, Pregação, Promoção Humana, para Família, seminaristas, Cristo Sacerdote, Para as Religiosas, Universidades, Para as Crianças, Fé e política. Conferir no site oficial: http://www.rccbrasil.org.br/portal/). (Steil, 2004; Oliveira, 2004; Prandi, 1997) Alguns calculam entre três e cinco milhōes de adeptos brasileiros (Pierruci; Prandi, 1996). Segundo dados da coordenação central (http://www.rccbrasil.org.br), há aproximadamente vinte mil grupos de oração registrados e cadastrados, com mais de um milhão de participantes efetivos, e os que eles chamam de membros "afetivos" que, embora se identifiquem com o movimento, não mantêm comprometimento, participando, ocasionalmente, dos grupos e eventos. Sua estimativa gira em torno de dez milhôes, entre visitantes esporádicos, telespectadores de programas de televisão e ouvintes de programas de rádio ligados às comunidades, padres e lideranças carismáticas. A construção de uma sede nacional, em uma cidade do interior de São Paulo, Canas, consolida um longo processo de institucionalização do movimento, tanto em termos simbólicos (por escolher como patrona a beata Elena Guerra, italiana do século XIX, devota do Espírito Santo), quanto em termos estruturais (http://www.rccbrasil.org.br/ portal/. Acesso em: 02 março 2014).

Debates do NER, Porto Alegre, ANo I5, N. 25, P. 215-239, JAN./Jun. 2014 
em 2010, 64,6\%. Em contrapartida, a presença dos evangélicos, em especial os pentecostais e neopentecostais, está em curva ascendente, saindo de quase nada em 1900, em 1910, até $22 \%$ em 2010. Um século de muitas lutas religiosas e transformaçōes culturais e sociais.

Nesse sentido, a estratégia de enfrentamento e restauração, exercida nos espaços políticos e públicos (mas também eletrônicos), somada à aliança tática e pontual com outros grupos religiosos (evangélicos e kardecistas) em torno de temas como a campanha antiaborto e autoridades do Estado caracteriza a posição dessa rede tradicionalista católica que emerge, entre outras formas, como uma comunidade eletrônica.

A atuação de grupos tradicionalistas não cessou de acontecer e hoje em dia ocorre de diversas formas, em especial nas mídias eletrônicas, e, por isso mesmo, as lideranças sacerdotais e leigas são imprescindíveis como fonte de estabilização e reprodução desses mesmos grupos. As mídias eletrônicas fornecem não só um espelho, mas tornam-se parte das estratégias de atuação dos grupos tradicionalistas católicos.

Dessa forma, a atuação de grupos tradicionalistas não cessou de acontecer e atualmente ocorre de diversas formas, entre as quais, as eletrônicas. O resultado desse processo é uma comunidade eletrônica portadora de dupla face: de um lado, pequenos grupos de católicos reunidos em torno de noções tradicionalistas de igreja, verdade e fé; de outro, grupos amplos, variáveis e nômades de pessoas que se identificam, em maior ou menor grau, com maior ou menor permanência, com essas noções religiosas. Um vaivém entre realidades socioeletrônicas.

Uma verdadeira rede de vínculos entre links e discursos tradicionalistas católicos no espaço cibernético permite sua expansão em três direções: as redes de relacionamento virtuais (Facebook, Twitter e outros), os blogs e as páginas eletrônicas em geral. De uma ou de outra forma, as famílias religiosas e as instituições serão confrontadas e interpeladas por essas novas modalidades de consumo, de comunicação e de construção da identidade (Hervieu-Léger, 1993; 2008).

Nesse novo cenário eletrônico, as instituições religiosas foram afetadas de diversas formas, uma vez que, além da cibernética, o consumo e a mídia

Debates do NER, Porto Alegre, Ano I5, N. 25, P. 215-239, JAn./Jun. 2014 
participaram como um dos elementos estratégicos de recomposição da memória de longa duração dos grupos religiosos. Ambos, consumo e mídia, tornaram-se veículos de criação, propagação e afirmação de fidelidades e estruturas de longa duração.

Como um dos diversos aspectos das novas tecnologias de comunicação, a internet instituiu uma "unidade de tempo sem lugar (graças às interações em tempo real por redes eletrônicas, às transmissões ao vivo [...]), continuidade de ação apesar de uma duração descontínua" (Lévy, 1999, p. 21).

Por esse motivo, a internet tornou-se um poderoso campo do real, constituindo uma interatividade livre, de difícil controle e estabelecedora de distintas direções no processo de comunicação (um-para-todos, todospara-todos, todos-para-um, um-para-um), com formas mais próximas ou mais distantes em relação às mídias tradicionais.

Nesse contexto de tecnologias eletrônicas interativas, em que "[...] ciberespaço permite [...] a convivência simultânea das mais diversas comunidades, construindo novas formas de comunicação, interação e simbologia" (Lévy, 1999, p. 240), emergem novas formas de comunicação próximas aos rituais tribais religiosos e às suas lógicas de participação de pensamentos mágicos.

O ciberespaço passa a ser o lócus em que a instituição religiosa (no caso, o catolicismo) oferece informações, práticas, bens e produtos a usuários anônimos, exceto os que deixam testemunhos e registram seus perfis e endereços eletrônicos, apesar de haver identidades simuladas, os conhecidos perfis fakes.

Nesse sentido, é possível argumentar que as novas mídias, em especial as redes eletrônicas de relacionamento, permitem a construção de uma comunidade católica imaginária (imaginação no sentido amplo, englobando realidades e símbolos) capaz de oferecer não só uma moderna via de expressão, como também um modo de estar-no-mundo, ancorado em uma ontologia tradicional.

A emergência de uma comunidade eletrônica católica tradicionalista, entendida como parte da construção de um discurso e um grupamento católico fundamentalmente híbrido: em meio às inseguranças da alta modernidade,

Debates do NER, Porto Alegre, ANo I5, N. 25, P. 215-239, JAN./Jun. 2014 
esse grupo, constituído por muitos jovens, é portador de uma ressemantização da tradição e uma ontologização política da mesma.

\section{LINGUAGENS HIPERMODERNAS E PERMANÊNCIAS SIMBÓLICAS}

Dentro dos novos quadros da modernidade, notam-se profundas transformações nas identidades religiosas herdadas, cuja transmissão das instituições, dos valores e das crenças de um grupo ou de uma sociedade às gerações posteriores é fundamental para sua continuidade no tempo, de forma que continuidade não significa imutabilidade: "[...] em todas as sociedades, a continuidade é garantida sempre na e pela mudança”. (Hervieu-Léger, 2008, p. 57).

A forma como a memória, os valores e as crenças religiosas institucionais são transmitidos sofreu mudanças, com rupturas e continuidades, de modo que se pode afirmar que não há transmissão sem crise da mesma transmissão. Por outro lado, com a radicalização das transformaçóes culturais e sociais na modernidade ocidental, entre as quais o vigoroso crescimento das mídias cibernéticas e da comunicação mediada por computador, a continuidade da memória e dos valores entre as gerações perdeu a importância para uma sociabilidade da experiência partilhada, da comunicação direta e do engajamento pontual (Hervieu-Léger, 2008).

As lacunas observadas entre o "[...] universo cultural das diferentes gerações não correspondem mais apenas aos ajustamentos que a inovação e a adaptação aos novos dados da vida social exigem", verdadeiras rupturas culturais atingem a relação com o mundo, especialmente a capacidade de comunicação dos indivíduos (Hervieu-Léger, 2008, p. 58).

As tensões geradas pela linguagem em rede remetem a significativos aspectos dos estudos culturais da religião:

As ciências sociais e as humanidades concebem as identidades como historicamente constituídas, imaginadas e reinventadas em processos constantes de hibridização e transnacionalização, os quais diminuem seus antigos enlaces

Debates do NER, Porto Alegre, Ano I5, N. 25, P. 215-239, Jan./Jun. 2014 
territoriais. Por outro lado, muitos movimentos sociais e políticos absolutismo o enquadramento territorial originário das etnias e nações, fixam dogmaticamente os traços biológicos e telúricos associados a essa origem como se fossem alheios às peripécias históricas e às mutaçôes contemporâneas (Canclini, 1999, p. 144).

Nesse sentido, a memória da religiáo, fio condutor que, ao ligar sujeitos individuais ou grupos sociais, renova lembranças e simbologias do religioso num movimento contínuo, é o meio pelo qual antigos discursos dogmáticos católicos reverberam nos meios eletrônicos, ao mesmo tempo em que funda as comunidades imaginárias virtuais (Camurça, 2009). Em contrapartida, trata-se de um tipo de memória que reifica o catolicismo "tridentino" (relativo ao Concílio de Trento, marco da Contrarreforma Católica), elegendo imagens, personalidades, documentos e expressões artísticas ligadas à grande tradição latina como elemento fundante da igreja. Em torno dessa memória, as comunidades eletrônicas católicas organizam-se, celebram e propagam-se.

A memória só é viva porque é vivida perdurando no tempo, e as representações-vivências do passado, por sua vez, no caso do campo das práticas religiosas católicas, serão tantas quantas forem os números de grupos existentes, renovando-se no espaço das vidas (Halbwachs, 1990).

Em contrapartida, trata-se de uma memória construída na forma de "rizomas", nem por isso menos real, na emergência do ciberespaço que, paradoxalmente, é uma linguagem ("estar-no-mundo") desenvolvida por jovens católicos tradicionalistas e outros simpatizantes. Esse "rizoma" de memórias em meio eletrônico permite uma identificação construída em fluxos, já que os mesmos “[...] não representam apenas um elemento da organização social, são expressões dos processos que dominam nossa vida econômica, política e simbólica” (Castells, 2005, p. 501).

Proporcionalmente aos avanços dos meios de comunicação, cresceu a insegurança em relação ao "outro" e ao "eu", ao "nós" e ao "eles". Como as antigas formas de perpetuação de ideais, valores, símbolos e materialidades sofreram significativas descontinuidades, os modos de construção identitária foram radicalmente alterados, e os processos de reprodução institucional foram liquefeitos (Canclini, 2000; 2008).

Debates do NER, Porto Alegre, ANo I5, N. 25, P. 215-239, JAN./Jun. 2014 
Profundamente afetado, o catolicismo concebe diversas respostas, desde a recusa e a indiferença até o uso seletivo e estratégico. Das muitas questôes que perpassarão as catolicidades, as mais prementes estão ligadas à legitimidade da memória, ou seja, o elo com o evento original fundador e sua continuidade no tempo sob uma forma específica (a tradição) e a posição diante das metamorfoses socioculturais da modernidade e das vizinhanças institucionais e sociais.

Em suas instâncias digitais, o catolicismo desenvolve linguagens e formas de pertença específicas que envolvem estratégias de gestão identitárias no novo espaço virtual: forte atuação nas redes sociais com a criação de perfis comunitários e pessoais com marcas simbólicas da tradição; adoção de personagens que simbolizam a tradição católica (santos, santas, papas conservadores e outros); uso de uma linguagem teológica conservadora, que oscila entre o uso de marcadores discursivos clássicos e marcadores semânticos. Esses marcadores usam imagens com slogans e memes, ou seja, montagens que fundem ditos humorísticos aforísticos com a imagem de alguém famoso, uma caricatura, um animal, uma cena de novela ou filme etc.

Vistos como elos sensíveis aos projetos de reprodução social dos catolicismos e participantes ativos nas redes sociais, os jovens constituem público-alvo dessas estratégias, atuando como consumidores e produtores.

Dessa forma, ao lado dos carismáticos católicos que investem pesadamente nos meios de comunicação e nas redes sociais, estão os tradicionalistas que, apesar de se autorrepresentarem como continuadores da tradição ou da longa e venerável Igreja Católica (ou do que imaginam que seja), têm diversidade de estilo, crença e pertença.

Constata-se, nas páginas eletrônicas (sites e redes de relacionamento virtuais), a emergência e a consolidação de expressões retóricas de uma juventude tradicionalista, de forma que captar e interpretar trajetórias e estilos retóricos desse tradicionalismo jovem é uma tarefa extenuante, quer seja pela dinamicidade do ciberespaço quer seja pelo desafio quantitativo e qualitativo.

Nesse âmbito, a pesquisa move-se num território volúvel e em permanente construção, dentro do qual o sentido da ordem, o fluxo de informações

Debates do NER, Porto Alegre, Ano I5, N. 25, P. 215-239, JAn./Jun. 2014 
e o quadro de controle são emergentes e descoordenados. Por isso, algumas perguntas, que neste texto são provocativas, demandam futuras pesquisas: Que página ou que grupo é representativo dessa juventude eletrônica? Quais critérios de representatividade são válidos para uma pesquisa antropológica no ciberespaço? Tendo essas indagações-bússola, pesquisaram-se algumas páginas eletrônicas mantidas por grupos jovens tradicionalistas católicos que serão expostas mais adiante.

\section{COMUNIDADE ELETRÔNICA CATÓLICA: TRADICIONALISMO E LINGUAGEM ONTOLÓGICA EM REDE}

Para mapear a presença das comunidades eletrônicas católicas, é preciso perceber como o catolicismo, particularmente no final da década de 1990, intensificou sua presença na internet e como foi absorvido pelo fluxo de linguagens. $\mathrm{O}$ catolicismo, particularmente a renovação carismática católica e os movimentos tradicionalistas, são os movimentos que mais disponibilizam páginas eletrônicas (Carranza, 2011; Silveira, 2009).

A simples quantificação dos sites relacionados ao catolicismo é tarefa inacabável, por vários motivos: primeiramente, pela quantidade crescente de páginas eletrônicas, perfis, blogs e outros ligados ao catolicismo; segundo, pela quantidade de buscadores ou dispositivos que elencam endereços eletrônicos; terceiro, pela existência de buscadores religiosos, como o buscador Busca.católica; quarto, pelo elevado grau de volubilidade e multiplicidade dos endereços eletrônicos; quinto, pela múltipla inserção das páginas eletrônicas em diversos buscadores simultaneamente. Contudo, utilizou-se o Google combinado com o buscador Busca.católica.

O desenvolvimento das redes sociais, a popularização de mecanismos de acesso e uso da internet (ferramentas de construção de sites e blogs, a convergência digital, permitindo acesso às redes por meio de uma base simples, como os celulares), abriu caminho para um ciberespaço católico tradicionalista e gerido em grande parte pela juventude identificada com retóricas discursivas antimodernas. 
Após pesquisar algumas centenas de páginas católicas, obteve-se o seguinte número, meramente ilustrativo:

Tabela 1 - Categorias e números de registro - 2013

\begin{tabular}{|c|c|c|c|c|}
\hline \multirow{2}{*}{\multicolumn{2}{|c|}{ Categorias }} & \multicolumn{2}{|c|}{ Tipo } & \multirow[b]{2}{*}{$\begin{array}{c}\text { Católico } \\
\text { tradicionalista }\end{array}$} \\
\hline & & $\begin{array}{l}\text { Católico } \\
\text { em geral }\end{array}$ & $\begin{array}{c}\text { Católico } \\
\text { carismático }\end{array}$ & \\
\hline \multicolumn{2}{|c|}{ Portais eletrônicos católicos } & 10 & 6 & 4 \\
\hline \multicolumn{2}{|c|}{ Comunidades } & 55 & 45 & 10 \\
\hline \multicolumn{2}{|c|}{ Dioceses } & 80 & 0 & 15 \\
\hline \multicolumn{2}{|c|}{ Entidades } & 110 & 80 & 10 \\
\hline \multicolumn{2}{|c|}{ Fundações } & 10 & 5 & 3 \\
\hline \multicolumn{2}{|c|}{ Meios de comunicação } & 25 & 10 & 5 \\
\hline \multicolumn{2}{|c|}{ Serviços e produtos } & 240 & 140 & 40 \\
\hline \multicolumn{2}{|c|}{ Bandas } & 24 & 24 & 0 \\
\hline \multicolumn{2}{|c|}{ Colégios e Faculdades } & 260 & 10 & 6 \\
\hline \multicolumn{2}{|c|}{ Organizaçôes religiosas masculinas } & 150 & 10 & 30 \\
\hline \multicolumn{2}{|c|}{ Organizações religiosas femininas } & 54 & 10 & 5 \\
\hline \multirow{3}{*}{ Pessoais } & Leigos & 80 & 40 & 20 \\
\hline & Padres & 40 & 20 & 25 \\
\hline & $\begin{array}{c}\text { Outras páginas } \\
\text { pessoais }\end{array}$ & 30 & 15 & 10 \\
\hline \multicolumn{2}{|c|}{ Total } & 1168 & 415 & 183 \\
\hline
\end{tabular}

Fonte: Pesquisa Pessoal, atualizada em 2013.

Examinando-se os espaços eletrônicos nos quais o catolicismo aparece como autor, produtor e fiador do discurso religioso, foram identificados durante a pesquisa três tipos principais: a) páginas institucionais de paróquias, dioceses, editoras católicas, associaçôes, grupos e movimentos mantenedores de um site oficial; b) páginas de comunidades e bandas (e outros) caracterizadas pela diversidade de estilos e pela quantidade de recursos interativos para o usuário; c) páginas pessoais, de adeptos ou de personalidades católicas, em especial de padres.

Debates do NER, Porto Alegre, Ano I5, N. 25, P. 215-239, JAn./Jun. 2014 
A estrutura dos sites mantém certo padrão: álbum de fotografias, chats, mural de mensagens, notícias, coluna de artigos ou crônicas escritas pelos respectivos padres ou convidados, altares virtuais, atalhos para pedidos de oração, horários de missa, atalhos para outras páginas católicas, música, divulgação de livros, CDs e DVDs de produção própria ou de outros. Um dado técnico observado na maioria das páginas católicas, embora não exclusivo das mesmas, é a existência de atalhos de compartilhamento com redes sociais, de impressão ou envio por correio eletrônico para outras pessoas ou grupos, além de atalhos para a introdução de comentários das notícias postadas. Nesse sentido, encontram-se muitas páginas desigualmente distribuídas pelas redes sociais (Facebook, YouTube e Twitter), em cujas páginas seus usuários operam passagens, um aspecto fundamental, mas que demandaria maior aprofundamento do que é possível neste artigo.

Para fins de pesquisa, serão feitos dois painéis: um painel ilustrativo, com algumas indicações quantitativas e qualitativas, tanto em redes sociais de franco crescimento (Facebook) quanto em blogs (páginas eletrônicas); outro painel, qualitativo, será analisado a partir de dois tipos de páginas eletrônicas: um perfil coletivo e um blog individual. A escolha, feita de maneira mais larga, recaiu em ambos em virtude dos seguintes fatores: quantidade de internautas que manifestaram algum tipo de concordância ou anuência; assuntos e temáticas abordadas (tradicionalistas); pelo fato de serem mantidos por jovens católicos tradicionalistas, divulgando imagens e textos relativos às polêmicas tradicionalistas. ${ }^{3}$

\section{SÍMBOLOS E IMAGINÁRIOS COMO CONSTITUIDORES DE COMUNIDADES ELETRÔNICAS CATÓLICAS}

Baseando-se na rede social eletrônica Facebook, com alta penetração no mundo ocidental e com milhões de usuários, as páginas eletrônicas católicas tradicionalistas estão nas principais línguas: inglês, espanhol, português, francês e italiano. São pequenos grupos, espalhados por diversas chaves temáticas: defesa da tradição, missa de São Pio $V$, católicos tradicionalistas entre outras.

3 Não será possível, por conta do espaço, dissertar mais detidamente sobre esses critérios.

Debates do NER, Porto Alegre, ANo I5, N. 25, P. 215-239, JAN./Jun. 2014 
Essas páginas estão distribuídas em três tipos de perfis: a) comunidades temáticas de tradição católica, que podem ser fechadas (participam apenas membros convidados ou aceitos pelo moderador) ou abertas (ampla participação, sem mecanismos de aceitação); b) grupos ou associações que defendem uma tradição católica; c) indivíduos ou fiéis católicos que assumem sua individualidade histórica ou simplesmente criam uma persona cibernética.

Outro instrumento de comunicação que se difunde rapidamente entre os carismáticos católicos são os blog, cujo conceito se expandiu e sua definição se tornou cada vez menos consensual em resultado da diversidade de formas, objetivos e contextos de criação, bem como da diversidade e distinta natureza dos seus criadores, de forma que neles são postados poesias, fotografias, animações, links para vídeos do Youtube, crônicas, desenhos e jogos, entre tantos outros.

Normalmente, as ferramentas de blog não determinam limite máximo de caracteres por post. O blog também indica um espaço de fluxos, construído no trânsito de acessos, comentários e microrrelaçōes no ambiente virtual. Alguns pesquisadores usam a metáfora da vizinhança para se referirem às redes de blogs, nas quais emergem espaços de discussão e construção de laços sociais. Os blogs são "[...] linkados uns nos outros e formam um anel de interação diária, através da leitura e do comentário dos posts entre os vários indivíduos, que chegam a comentar os comentários uns dos outros ou mesmo deixar recados para terceiros nos blogs" (Recuero, 2003, p. 7).

A metáfora da vizinhança é questionada por outros pesquisadores porque, para se ler um blog/texto, não é necessário visitar o blog/espaço em seu endereço na Web. Alguns blogs oferecem o recurso de feed (RSS ou $\mathrm{XML}$ ) que permite a leitura dos posts (ou postagens) em programas denominados agregadores de noticias. Esse tipo de software, funcionando como um sistema de assinaturas, confere periodicamente se existem novos posts nos blogs cadastrados. Caso haja novidades, tais agregadores listam automaticamente os posts, dispensando o internauta de visitar todos os blogs/ espaço para conferi-las. Se por um lado esse recurso resulta em economia de navegação, por outro, afasta os posts de seu contexto original, uma vez que eles são paralelos a outros textos, links, imagens e do próprio layout

Debates do NER, Porto Alegre, Ano I5, N. 25, P. 215-239, Jan./Jun. 2014 
da página construído segundo as preferências do blogueiro. Todos esses elementos formam um todo significante que compóe o blog.

Dessa forma, as definições de blogs como publicação de microconteúdo ou como diário íntimo são limitadas, por se relacionarem a um tipo específico de blog/texto ao uso do blog/programa. Desde simples arquivo de links úteis, enriquecido de comentários ou descrições do autor, passando por registros digitais de reflexões e/ou sentimentos até espaço para troca de ideias e confronto de perspectivas, procurando a aprovação pública e incentivando a participação dos visitantes, o blog tem seu nível de visibilidade pública consonante com seus autores, com a comunidade em que se insere, com o tema, entre outras variáveis.

Alguns indicadores evidenciam a existência de uma comunidade de blogs: a) ideias similares que perpassam diferentes blogs; b) laços comunais indicados pela leitura continuada dos mesmos blogs e pela relação das listagens de links entre blogs; c) padrões de linkagem e interconexão de blogs evidenciando valor e recomendação de outros blogs a partir da percepção do blogueiro; d) o conjunto de opinióes emergentes a partir do post em um blog, indicando o contexto compartilhado e um sistema de relacionamentos entre os interagentes; e) menção da participação nos mesmos encontros (Komesu, 2004). Todo esse conjunto facilita o fortalecimento de relacionamentos e o desenvolvimento de novas relações.

O crescimento da rede de blogs católicos contribuiu para aumentar os laços de reciprocidade a ponto de se criar o termo blogosfera católica para abarcar as relaçôes e trajetórias do fluxo de identificação com aspectos religiosos do catolicismo. Desde 2007, os blogs católicos utilizam o termo blogosfera católica para se referir às redes de interação entre os autores e os internautas, independentemente de sua ligação com o catolicismo.

Nesse ambiente chamado blogosfera, as polêmicas ou as correntes de opinião são histórias que reagem a algo ocorrido na mídia de massa ou a algum fato, destacado e apresentado. A partir da postagem, em pouco tempo, diversos comentários são postados e podem ser votados (voto positivo ou negativo). Os eleitores apontam as opiniōes originais. Outros autores de opinião acrescentam mais à história com posts (mensagens escritas ou

Debates do NER, Porto Alegre, ANo I5, N. 25, P. 215-239, JAN./Jun. 2014 
imagens) de reação, fornecendo mais que um simples voto, num círculo contínuo, cujo desfecho terá duas direções: ou um blogueiro resumirá a história ou ela se perderá no ciberespaço. Acompanhar os desdobramentos das discursões fora da rede eletrônica, naquilo que foi chamado de interação face a face, é um desafio e, fará parte de futuras pesquisas, já que o recorte é o ambiente eletrônico.

Entre as comunidades eletrônicas católicas tradicionalistas, três eixos temáticos capturam e impulsionam comentários, participações, crônicas, discursos e linguagens: o eixo moral (aborto e casamento gay); o eixo litúrgico-teológico (tradição católica, missa tridentina e mudanças ou permanências no governo da igreja); o eixo político-social (defesa de aspectos conservadores ou de direita no campo político).

Esses eixos não mobilizam igualmente diversas faixas etárias. $\mathrm{O}$ eixo moral costuma mobilizar a juventude menos engajada no catolicismo tradicional, cuja postura é politicamente conservadora em termos morais. O eixo litúrgico-teológico, em contrapartida, mobiliza os jovens que se assumem como tradicionalistas, que não raro se veem em uma batalha preciosa e fundamental contra os modernismos, vistos como desvirtuamento da grande e vigorosa matriz católica.

Um dos blogs mais acessados, quiçá o mais representativo da retórica tradicionalista no Brasil, é o Fratres in Unum, ligado a Fraternidade Sacerdotal São Pio $\mathrm{X}^{4}$, citado pelo blogueiro de $O$ possivel e o extraordinário. Deve-se

4 Organização católica ultraconservadora que nega o Concílio Vaticano II. Fundada em 1970 por Dom Marcel Lefebvre. Em 2001, segundo propaganda eletrônica, contavam com 463 sacerdotes, 85 Irmãos, 157 Irmãs, 75 Oblatas, 160 Seminaristas, presente em 30 países com 13 Distritos e 6 Casas Autônomas, 6 Seminários, 159 priorados, 725 igrejas, 83 escolas (Ensino Básico e Ensino Médio) e 2 universidades, 10 casas de exercícios espirituais. Fonte: http://www.fsspx-brasil.com.br/page\%2001.htm. O site atual é: http://www.fsspx-brasil.com.br/exe2/. Nessa nova versão, os dados mudam, sendo assim apresentados: "Possui seis seminários, dois pré-seminários (Gabão e Filipinas) e um pequeno seminário (Austrália). É constituída por 161 priorados espalhados por 63 países e servidos por 529 sacerdotes e dizem "guardar a Tradição Católica e buscar a vivência na Verdade Imutável”. No Brasil, exercendo seu apostolado através de 5 sacerdotes, sem contar os padres e comunidades amigas, a Fraternidade dirige dois Priorados (São Paulo/SP e Santa Maria/RS), diversos centros de Missa e presta auxílio às muitas

Debates do NER, Porto Alegre, Ano I5, N. 25, P. 215-239, JAn./Jun. 2014 
ressaltar que ambos fazem referências recíprocas como também fazem referência a outros blogs e páginas tradicionalistas. Nesse blog, todos os eixos estão presentes: política, moral e liturgia alternam-se com comentários, imagens, posicionamentos e discussões refinadas de cunho teológico e filosófico.

Em funcionamento desde 2008, pretende, por meio de fotografias, animações e outros instrumentos, "[...] potencializar a luta contra o relativismo expressivo que constitui a panaceia 'filosófica' dos teólogos modernistas" . O número de visitantes talvez seja representativo de sua importância: mais de seis milhões de visualizações, milhares de comentários e centenas de seguidores em seus posts. A página Fratres in Unum era dividida em colunas, mas passou por uma nova configuração.

Há postagens diárias ou semanais cujos textos e imagens são alternados para catequizar o leitor. Os arquivos de postagem recuam até 2008, com muitos comentários, muitas análises e tomadas de posição tradicionalista. Nesses fluxos, a doxa católica permanece viva, doxa enquanto o consenso histórico hierárquico sobre o que é o certo, o correto, o que está dentro de uma linha hegemônica de teologia. No dia dezenove de agosto de 2011, por exemplo, chamou a atenção a seguinte postagem: a fotografia de uma igreja "o serviço litúrgico ou missa tridentina no templo do bairro Barreira do Triunfo na cidade de Juiz de Fora, Minas Gerais" a página mudou de desenho, adquirindo a forma de um blog: http://fratresinunum.com/.

Mantido por católicos que se afirmam defensores da tradição, o blog veicula ou, de acordo com a linguagem cibernética, compartilha constantemente, notícias de outros blogs e páginas tradicionalistas. Grafado em latim

comunidades amigas tradicionais que o solicitam. Os sacerdotes da Fraternidade celebram exclusivamente a Missa Tradicional, dita de São Pio V, em latim [...] Este Portal na Internet é mantido pelos sacerdotes do Priorado Padre Anchieta, localizado em São Paulo/SP [...]".

5 Conferir: http://fratresinunum.com/. O trecho do texto se encontra em: <http://www. fratres.rg3.net>. Acesso em: 10 nov. 2013.

6 Conferir: http://fratresinunum.com/2011/08/19/summorum-pontificum-no-brasil-missa-tradicional-em-juiz-de-fora-mg-2/. Acesso em: 10 nov. 2013.

Debates do NER, Porto Alegre, ANo I5, N. 25, P. 215-239, JAN./Jun. 2014 
(Frates et Unum), o blog defende posições ultratradicionalistas e comenta com argúcia, as mudanças, os rumos e perspectivas internas da igreja. No caso da notícia sobre a possível nomeação de um prelado, conforme imagem descrita, um trecho indaga sobre as possíveis nomeações e mudanças a serem feitas:

Significa que as mudanças na liturgia do Papa serão rápidas. Um novo estilo se instalou, para desespero daqueles preocupados com a coerência de uma reforma da reforma. Não é possível afirmar, com honestidade, que Francisco continua no caminho da reforma da reforma iniciado por Bento XVI, ainda que de forma diferente ${ }^{7}$.

Um comentário dessa postagem, anexado por um jovem católico que adotou o nome de Marcelo, elucida a linguagem moderna imiscuída na doxa católica:

Parafraseio esse comentário e digo: ..."tento abafar a mágoa dolorida em meu coração que tenho de Bento XVI”... Bento XVI, tomara Deus que sem querer, jogou por terra todo seu trabalho de Reforma da reforma, que, ninguém em sã consciência, acredita que ainda exista... Mas, como se diz no nordeste, "Deus não bate em ninguém de cacete". Apesar de debilitado e fraco fisicamente, Bento XVI está lucidíssimo e com certeza vendo com dor e amargura o mau que produziu sua renúncia, pois o mesmo sabe, e afirmou num dos seus escritos, que uma das causas da crise da fé é a crise litúrgica, e pelo balançar da carruagem Franciscana, a era depredatória Montiniana ${ }^{8}$ pós-Concílio está de volta, mais forte do que antes... Por que Deus permitiu isso??? Não nos cabe saber... Só peço e desde já rezo a Deus, como pediu o moderador deste blog, que nada nem ninguém te impeça ou intimide no serviço que tens prestado à Igreja, denunciando e pondo às claras os desmandos e aberrações que acontecem pelo Brasil e mundo a fora em matéria litúrgica. Muitas vitórias já foram alcançadas graças ao trabalho incansável desse blog na defesa da Fé Católica. Se os maus não dormem nem cochilam, por que os filhos da luz deveriam se calar??? Contem com nossas orações e reze por nós!

7 Conferir: http://fratresinunum.com/2013/09/28/iniciada-a-reforma-da-reforma-da-reforma-liturgica/. Acesso em: 25 set. 2013.

8 Refere-se ao sobrenome do Papa Paulo VI: Montini.

Debates do NER, Porto Alegre, Ano I5, N. 25, P. 215-239, JAn./Jun. 2014 
A partir do comentário, é possível notar que a tradição é defendida pelo engajamento emocional, de modo que assume um tom subjetivo que articula a ideia de continuidade (a Igreja, a Tradição, a Não Mudança) e a de descontinuidade (panorama liberal). O leitor em questão comenta outro comentário feito pelo internauta Bruno Luís Santana, autor de um blog de defesa da tradição. O desabafo emocional desse jovem blogueiro tradicionalista contra o papado modernista de Francisco encontrou empatia de 54 pessoas e a antipatia de quatorze pessoas. As curtidas, popularizadas pelo Facebook, são retratos, ainda que momentâneos, de identificaçōes e desidentificações ou trilhas de socialidade cibernética.

Os tags ou marcadores (palavras que remetem a um conteúdo arquivado do site) e outros blogs, bem como as páginas eletrônicas recomendadas são bons indícios para um mapeamento semântico, uma vez que esses marcadores giram em torno de alguns eixos axiais: tradição, padres, cardeais, antiga liturgia católica tridentina, personalidades tradicionalistas (as que romperam com o Vaticano II), crise pós-conciliar, entre outros. Trata-se de centenas de postagens: artigos, crônicas, pequenos comentários, vídeos, entre outros.

Com relação à rede de páginas interligadas ou às páginas recomendadas, a pesquisa contabilizou pelo menos 180, entre blogs e sites, dos quais pelo menos cem citam os mesmos blogs e páginas eletrônicas. Vale destacar algumas categorias semânticas, com breves comentários:

a) padres e ordens religiosas tradicionalistas: os posts e comentários referem-se à tradição católica que transparece uma reificação da missa tridentina e do Concílio de Trento. As imagéticas remetem a uma guerra cultural contra a Igreja Católica. Páginas: Blog do Pe. De Tanouarn, Blog do Pe. Demets, Blog do Pe. Laguerie, Bénédictins de l'Immaculée, Padre Demétrio, Pe. Marcelo Gabert Masi - Catolicismo Inteligente, Zelo Zelatus Sum - Pe. Elcio Murucci, Via-Veritas-Vita - Pe. Elcio Murucci, Mundo Eclesial, Pe. Michael Rodriguez, Revue Item - Pe. Aulagnier. Mosteiro de Bellaigue, Mosteiro Santa Maria (carmelitas tradicionais);

b) organizações de defesa tradicionalista: trata-se de organizações que estiveram em rota de colisão com o Vaticano, por desprezarem e desconsiderarem o Concílio Vaticano II. Nas gestôes dos Papas João Paulo II e Bento 
XVI, houve tentativas de aproximação, mas essas organizações, em graus variados, ou exigiram mais condiçōes ou aceitaram as condiçôes do Vaticano e foram legitimadas. Páginas: Fraternidade Sacerdotal Pio X - Brasil, Grupo São Tomás (Boston - EUA), Institut du Bon Pasteur, Institution l'Angélus - IBP, Secretum Meum Mihi, Instituto Cristo Rei, Fraternité Saint-VincentFerrier, Fraternidad de Cristo Sacerdote y Santa María Reina, Fraternidade São Pedro, DICI - Fraternidade Sacerdotal São Pio X;

c) defesa da Tradição Católica: uma variação dos dois primeiros (os itens a e b da lista acima), que também tem tendência a enfatizar a ideia de ruptura entre a configuração da Igreja, após o Concílio Vaticano II, e a configuração anterior, vista senão como a mais autêntica e verdadeira. Exemplos: Canal Maria Santíssima, Católico Apostólico Romano, Católicos Alerta!, Católicos de Ribeirão Preto, Catholic Cartoon Blog, Catholic Church Conservation, Contra Impugnantes, Creer en Mexico, Cruzados de Maria, A Vida Sacerdotal, Adversus Haereses, Aliança Sacerdotal, Arena da Teologia, Deus lo vult!, Devoción Católica, Disputationes Theologicae (Francês), Disputationes Theologicae (Italiano), Excerptos ou Fragmentos, Exsurge Domine, Extra Ecclesiam Salus Nulla, Família Beatae Mariae Virginis, Igreja Una, Tradi News, Tradição Católica, Tradição Católica em Vitória-ES, Traditional Vocations blog, Transalpine Redemptorists at home, Tribuna, Lepanto, Administração Apostólica São João Maria Vianney; Associação Civil Santa Maria das Vitórias - Anápolis (GO), Associação Cultural Santo Tomás; Associação São Pio V, Capela Nossa Senhora das Alegrias-Vitória/ ES, Católicos Online, Catholic World News.

d) missas tridentinas: páginas dedicadas à divulgação do ritual de Pio $\mathrm{V}$, o Papa mais ativo da Contrarreforma. O ritual tridentino mobiliza alguns jovens tradicionalistas, que o defendem nos comentários. Um documento de Bento XVI, 'Motu proprio' Summorum Pontificum, sugere que a forma litúrgica tridentina não foi ab-rogada, constituindo-se mais uma expressão extraordinária do rito eucarístico. Esse documento permitiu aos tradicionalistas aproximarem-se da Igreja e exercerem o ritual da missa. Exemplos: Messa in Latino, Missa Tridentina em Belo Horizonte, Missa Tridentina em Betim - MG, Missa Tridentina em Brasília, Missa Tridentina em Portugal, Missa Tridentina em São Carlos, Sancta Missa - Portugal, Missa Tridentina em Franca.

Debates do NER, Porto Alegre, Ano I5, N. 25, P. 215-239, JAn./Jun. 2014 
e) juventude tradicionalista: nesses sites, os três eixos abordados são explanados, explicados, defendidos. Exemplo: Juventutem Londrina, Juventutem Michigan, Juventutem Niterói, O Cristão Comprometido, O Possível e O Extraordinário, O Segredo do Rosário, O Tradicionalista, O Ultrapapista Atanasiano, Oblatvs.

Outra característica dessas páginas tradicionalistas são as orações em latim e/ou em português, todas antigas e retomando a tradição, a pureza, a autêntica fé cristã. Por fim, é preciso perceber que a comunidade eletrônica tradicionalista católica é feita de muitos outros sites ultraconservadores, muitos dos quais ligados à Igreja Católica na cidade de Campos (RJ) e outros ligados a associações ultraconservadoras, como a Fraternidade Sacerdotal São Pio X.

Uma página muito citada pela juventude nas redes sociais é a Frente Universitária Lepanto, ${ }^{9}$ de estudantes universitários católicos, em cuja página pode-se ler: "Afirmamos e proclamamos a certeza de que a Pós-modernidade não será a era do caos e da anarquia, mas, pelo contrário, será o tempo da restauração da Civilização Cristã, sem a qual o mundo soçobrará"10.

Segundo seu organizador, o movimento foi criado em 1998, em Brasília, e a página eletrônica, em 2002, estando presente em dez estados brasileiros, com um cadastro de doze mil interessados e participantes ${ }^{11}$.

Com portfólio amplo e abarcando artigos de sociologia e política, seu eixo aborda também a moral: homossexualidade, pesquisa com células-tronco e outros assuntos correlatos. Foram publicados ainda boletins eletrônicos, destacando-se o número 01, de maio de 2008:

O que queremos hoje já não é ser moderno! O moderno saturou, cansou e não deixou saudades. É hora de redescobrir o passado esquecido e caluniado, os

9 Conferir: http://www.lepanto.com.br/dados/index.html. A página é mantida por estudantes universitários católicos conservadores. Acesso em: 10 nov. 2013.

${ }^{10}$ Conferir: http://www.lepanto.com.br/dados/Finalidades.htm. Acesso em: 10 nov. 2013.

11 Conferir: http://www.lepanto.com.br/dados/EntrevistaLep.html. Acesso em: 10 nov. 2013. O fundador se chama Frederico Viotti, apresentando-se como bacharel em Direito e em Ciência Política pela Universidade de Brasília, apresenta-se como responsável pela Frente Universitária Lepanto e pelo boletim Post-Modernidade, sendo também pesquisador na área da História da Igreja e de apologética católica.

Debates do NER, Porto Alegre, ANo I5, N. 25, P. 215-239, JAN./Jun. 2014 
valores que não morrem com o tempo. Passado bendito de nossos antepassados, futuro esperado de nossos descendentes. Um futuro baseado em um verdadeiro progresso, isto é, no reto aproveitamento das forças da natureza, segundo a Lei de Deus e a serviço do homem. Mostraremos que a nossa geração não foi omissa e deixou a História passar como quem assiste a um cortejo. Façamos nós esse cortejo. O cortejo inaugural de uma outra Era Histórica nascida sobre a sepultura do falso conceito de modernidade!

Triunfalista, a linguagem repercute os grandes documentos papais que até o Concílio Vaticano II condenavam a modernidade, associando-a a ideias de liberdade absoluta (como degeneração moral e violência total) e igualdade absoluta (como excrescência política e econômica). O passado é exaltado, mas, ao mesmo tempo, dois conceitos de modernidade são percebidos, um seria falso, e outro, verdadeiro; este seria o "reto aproveitamento das forças da natureza, segundo a Lei de Deus e a serviço do homem". No post mais recente, política, moral e religião mesclavam-se:

O pedido ao Papa Francisco não foi transmitido pela CNBB e o Papa não falou com a Presidente sobre o tema. Nosso último post assim encerrava: "Oxalá o Romano Pontífice possa de fato falar com a presidente Dilma pedindo-lhe o VETO INTEGRAL do tal projeto abortista, pois, como reza a expressão latina: "Roma locuta, causa finita" ('Roma falou, a causa está encerrada') ou seja, o veto total estará garantido!"12.

Uma nostalgia da autoridade tradicional e um romantismo ressentido em torno de uma concepção da vida instauram-se como sagrados e absolutos. Soma-se a essa nostalgia a impressão de que a moralidade católica se torna lócus de luta representacional desses grupos tradicionalistas que transitam nas mídias eletrônicas.

Paradoxalmente, nos tempos da grande rede, o território físico deixou de existir como ancoradouro do movimento de fixação identitária atemporal e a-histórica, de forma que o dogma religioso tornou-se o novo ancoradouro.

12 Conferir: http://www.lepanto.com.br/sociologia-e-politica/mais-um-dia-de-luto-nahistoria-do-brasil-1o-de-agosto-de-2013/. Acesso em: 27 set. 2013.

Debates do NER, Porto Alegre, Ano I5, N. 25, P. 215-239, Jan./Jun. 2014 
Nesse contexto, para que a tradição seja reavivada e a salvação seja um ato divino presente entre homens e mulheres, é preciso que a ela seja constantemente reconfigurada e apareça nas capas e nos brilhos dos produtos.

\section{CONSIDERAÇŌES FINAIS}

O fluxo de linguagens eletrônicas está sujeito a hibridaçôes por meio das quais os sujeitos religiosos são reconstruídos como nódulos de uma extensa rede (onde ocorre o trânsito do fluxo) que imbrica o dogma, o trânsito de emoções e corpos, operando-se o ajustamento emotivo e interpretativo entre a gramática (a grande tradição) e a performance (manifestação dos sentimentos ou emoções nas novas linguagens).

Constata-se, portanto, que a ambiguidade semântica pauta o comportamento de alguns segmentos da Igreja Católica e do catolicismo no contemporâneo cenário midiático-consumerista, por força do confronto entre a lógica totalizante católica e a dinâmica fragmentária e autônoma dos meios de comunicação e marketing. Diante disso, pode-se perceber que estão em curso, diversos projetos de perduração identitária, valendo-se do longo, imenso e complexo repertório de teologias, imagéticas, símbolos, discursos e materialidades católicas.

Com combinações e usos específicos, mais próximos ou mais distantes entre si, cada projeto procura valer-se das mídias em graus e formas diversas, promovendo a dispersão da memória, submetida a pontos de fuga, recombinações e ressemantizações, mas, ao mesmo tempo, expandindo-se e sendo apropriada, de múltiplas formas, pelos usuários.

Por outro lado, do ponto de vista da produção, a memória católica apresenta-se em torno de alguns eixos de longa duração, em especial os relacionados à moralidade, liturgia e política, e nos quais emergem polarizaçôes, adesōes, defesas e ataques. A investigação em torno das páginas eletrônicas tradicionalistas e de sua retórica demonstra que, em sua maioria, os produtores, adeptos e consumidores do projeto tradicionalista são católicos que já tinham práticas próximas de uma retórica inflamada, com ressentimentos românticos.

Debates do NER, Porto Alegre, ANo I5, N. 25, P. 215-239, JAN./Jun. 2014 
Ressalta-se que, nas teias dessa retórica, a linguagem estética da modernidade penetrou de forma indelével, ou seja, a tradição católica, ao perder suas bases sociais de reprodução, lançou-se no marketing, no consumo e no mundo cibernético para garantir sua reprodutibilidade simbólica e social.

De fato, as novas mídias eletrônicas oferecem tanto uma moderna via de expressão para antigos discursos dogmáticos quanto um modo de estar-no-mundo, arraigado em uma concepção retromodernista da tradição católica que ora se opóe ao laicismo, ora instrumentaliza a ideia de liberdade religiosa.

Procurando convencer católicos praticantes da verdade e da autenticidade de uma determinada forma e estilo de viver o catolicismo, o projeto conservador tende a tradicionalizar. Talvez já seja mais um adendo no campo da pluralidade interna do catolicismo, uma voz ruidosa, mas dependente dos meios eletrônicos para ser ouvida, vista, comentada e consumida, dentro e fora da Igreja Católica.

\section{REFERÊNCIAS}

CAMURÇA, Marcelo A. Tradicionalismo e meios de comunicação de massa: o catolicismo midiático. In: CARRANZA, Brenda; MARIZ, Cecília; CAMURÇA, Marcelo. Novas comunidades católicas: em busca do espaço pós-moderno. Aparecida: Ideias \& Letras, 2009. p. 59-78.

CANCLINI, Néstor Garcia. Narrar o multiculturalismo. In:

Consumidores e cidadãos. Conflitos multiculturais da globalização. Rio de Janeiro: Editora UFRJ, 1999. p. 143-162.

. Culturas híbridas: estratégias para entrar e sair da modernidade. São Paulo: EDUSP, 2000.

. Leitores, espectadores e internautas. São Paulo Iluminuras, 2008.

CARRANZA, Brenda. Renovação carismática católica: origens, tendências, mudanças. Aparecida: Santuário: 2000.

. Catolicismo midiático. Aparecida: Ideias \& Letras, 2011.

Debates do NER, Porto Alegre, Ano I5, N. 25, P. 215-239, JAn./Jun. 2014 
CASTELLS, Manuel. A sociedade em rede. A era da informação: economia, sociedade e cultura. 8. ed. São Paulo: Paz e Terra, 2005.

GIDDENS, Anthony. A vida em uma sociedade pós-tradicional. In:

Em defesa da sociologia. Ensaios, intepretações e tréplicas. São Paulo: Editora UNESP, 2001.

HALBWACHS, Maurice. A memória coletiva. São Paulo: Vértice, 1990.

HERVIEU-LÉGER, Danièle. La religion pour mémoire. Paris: Éditions du Cerf, 1993.

O peregrino e o convertido. A religião em movimento. Petrópolis, 2008.

KOMESU, Fabiana. Blogs e as práticas de escrita sobre si na internet. In: MARCUSCHI, Luiz A.; XAVIER, Antônio C. (Orgs.). Hipertexto e gêneros digitais: novas formas de construção do sentido Rio de Janeiro: Lucerna, 2004. p.110-119.

LÉVY, Pierre. O que é o virtual? São Paulo: Editora 34, 1997.

Cibercultura. São Paulo Editora 34, 1999.

MAFESSOLI, Michel. Sobre o nomadismo: vagabundagens pós-modernas. Rio de Janeiro: Record, 2001.

OLIVEIRA, Eliane Martins de Oliveira. O Mergulho no Espírito Santo. Religiāo e Sociedade, Rio de Janeiro, v. 24, n. 1, p. 96-98, 2004.

PIERUCCI, Antonio Flávio; PRANDI, Reginaldo. A realidade social das religióes no Brasil. São Paulo: Hucitec, 1996.

PRANDI, Reginaldo. Um sopro do Espírito. São Paulo: Edusp/Fapesp, 1997.

RECUERO, Raquel da Cunha. Weblogs, Webrings e Comunidades Virtuais. Revista Sessões do imaginário, v. 1, n. 31, 2003.

. Webrings: As Redes de Sociabilidade e os Weblogs. Sessóes do imaginário, Porto Alegre, v. 11, p. 19-27, 2004. 
SILVEIRA, Emerson J. Sena da. Linguagens e Fluxos Midiático-Consumeristas no Catolicismo Carismático. Estágio Pós-Doutoral com bolsa pelo CNPq na área de concentração: Ciências Sociais da Religião. Departamento/Programa de Pós-Graduação em Ciência da Religião, Instituto de Ciências Humanas, Universidade Federal de Juiz de Fora, 2014. (Texto avulso).

STEIL, Carlos Alberto. Renovação Carismática Católica: Porta de Entrada ou de Saída do Catolicismo? Religião e Sociedade, Rio de Janeiro, v. 24, n. 1, p. 28-31, 2004.

Recebido em: 15/01/2014

Aprovado em: 13/03/2014 